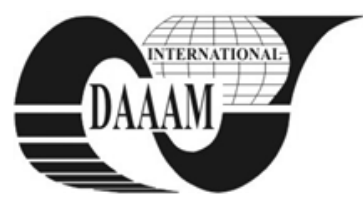

Annals of DAAAM for 2011 \& Proceedings of the 22nd International DAAAM Symposium, Volume 22, No. 1, ISSN 1726-9679 ISBN 978-3-901509-83-4, Editor B. Katalinic, Published by DAAAM International, Vienna, Austria, EU, 2011 Make Harmony between Technology and Nature, and Your Mind will Fly Free as a Bird Annals \& Proceedings of DAAAM International 2011

\title{
PARALLEL KINEMATIC STRUCTURES AND THEIR INNOVATIVE APPLICATIONS
}

\author{
POPPEOVA, V[iera]; BULEJ, V[ladimir] \& URICEK, J[uraj]
}

\begin{abstract}
In this paper are described the mechanisms with parallel kinematic structure, which have become a common part of mechanical engineering praxis. In research laboratories as well as in companies around the world there were developed also some interesting, innovative and less-known mechanisms within last ten years. Many of them were created for specific nonstandard applications and than they are unique, for example Mechanism IPAnema 2, SwarmItFIX, HexaBend etc.
\end{abstract}

Key words: parallel kinematic structure, application, manipulation, parallel kinematic machine

\section{INTRODUCTION}

The general mechanisms with parallel architecture have the end-effector (platform) connected to the frame (base) through a number of kinematic chains (legs). Stewart presented his platform in 1965. Until today there were designed about 200 different architectures of PKS (Merlet, 2000).

During the study of the literature, participation the conferences, summer schools and during the international trade fairs we have met with a number of different applications. The most frequent are still the devices with PKS for machining and for manipulation. Besides these standard applications, we also had the opportunity to find many interesting, less-known but very useful variations of machines with PKS.

\section{PKS APPLICATIONS IN GENERAL MECHANICAL ENGINEERING}

\subsection{Cable-driven Parallel Robot for Manipulation within a} Large Workspace

An idea to automate the handling operations also within the much larger workspace arises according to the advent of large engineering projects (building of hydro power plants, bridges, highways, etc.). The general cable-driven parallel robot consists of a rigid frame, a mobile platform, and winches which control the cable lengths. Coordinated motion of the winches allows moving the mobile platform on arbitrary spatial trajectories to fulfill tasks such as handling, assembly, and taking measurements.

One example of novel 6-DOF cable-driven robot was developed by the team at State Key Laboratory of Virtual Reality Technology and Systems in Bejing (Li et al., 2010).

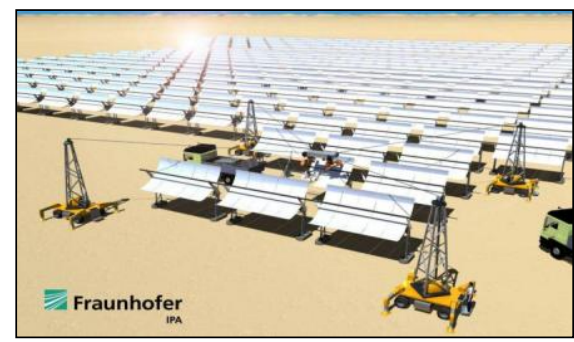

Fig. 1. Mechanism IPAnema2 (Pott, 2010)
Another example is the mechanism IPAnema2 (Fig. 1) designed by Fraunhofer IPA, Stuttgart (Pott, 2010), which can be an appropriate solution for the solar power plants assembly.

\subsection{Self-reconfigurable Fixture System for Machining of Thin-sheet Parts (SwarmItFIX)}

The team leaded by professor Rezia Molfino in PMARlab (University of Genoa, Italy) is currently involved in an international project (the partners are also VVU Kosice and company Exechon) oriented on the development of a selfreconfigurable fixture system (Zoppi, 2010). The envisioned fixturing strategy uses mobile parallel manipulators (fixturing agents) continuously repositioning to provide support to the thin-sheet workpiece near the moving tool. Several possible designs with different locomotion principles were developed (fig. 2). The main requirements are rapid and precise locomotion.

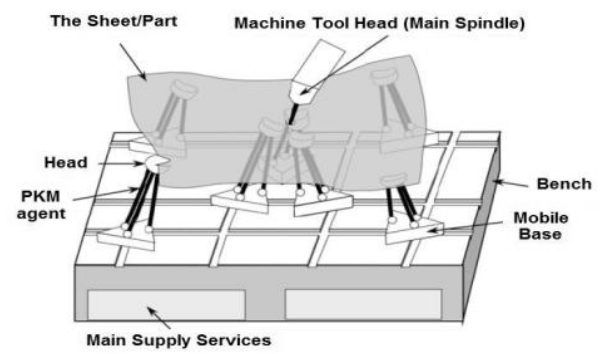

Fig. 2. Self-reconfigurable fixture system for thin-sheet workpieces called SwarmItFIX (Zoppi, 2010)

\subsection{Wide-range Parallel Six-axes Force/Torque Sensor with Flexible Joints}

The compact design of any parallel mechanism with more DOF predetermines it for force/torque sensor application. The parallel six-axis force/torque sensor designed at Yanshan University in China (Fig. 3) is a kind of measuring instrument which has the ability to detect the forces in axes $\mathrm{X}, \mathrm{Y}$ and $\mathrm{Z}$ and the moments around these axes simultaneously (Zhao et al., 2010). This kind of sensors is widely used for applications where is needed force/torque - position control such as for parts scanning, contour tracking, precise assembly, etc.

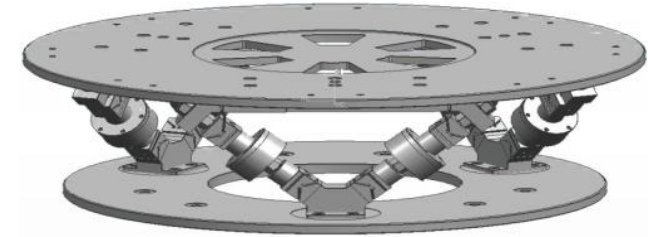

Fig. 3. Parallel Six-axis Force/Torque Sensor with Flexible Joints (Zhao et al., 2010)

\subsection{Flexible bending machine for tubes and profiles (HexaBend)}

Innovative manufacturing techniques to produce components for lightweight constructions are demanded for 
new part design principle. A positive answer to this demand could be a technology based on kinematic shaping of the tube or profile. A forming technology to make stereometric freedom bending parts as pre-forms for hydroforming processes or ready-for-use space-frame components was introduced in (Neugebauer, 2002) together with a newly developed machine (Fig. 4) and technology concept. The core of the system is based on 6DOF hydraulic parallel kinematic structure (hexapod) which applies forces to the active bending tool. HexaBend can by applied for flexible small series production in prototyping.

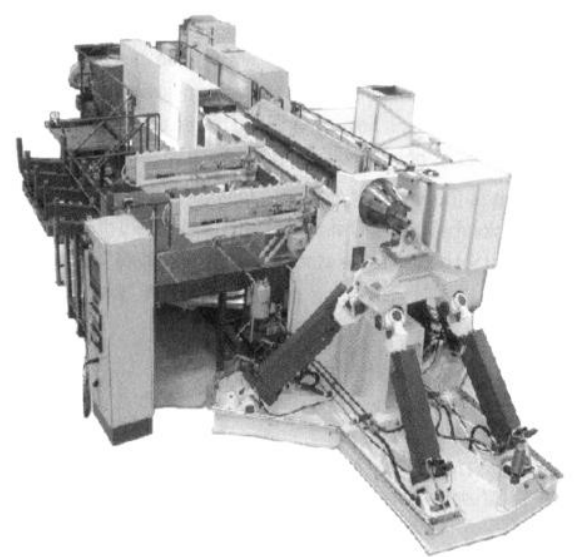

Fig. 4. The overall view and the structure of HexaBend (Neugebauer, 2002)

\subsection{Micropositioning devices based on PKS}

In the field of micro/nano scale manipulation, micromanipulators with ultra-high precision are urgently required to perform such tasks as bio-cell manipulation, optical fibers alignment, micro device assembly, and operation under scanning probe microscopes, etc. ( $\mathrm{Li}, 2004)$. The attributes such as high rigidity, high load carrying capacity, and high accuracy have endowed compliant parallel manipulators (CPMs) with potential ability in micro or nano scales precision operations. The 3-PRC CPM with flexible hinges and piezoelectric actuators designed at Yanshan University in China is illustrated in figure 5 .

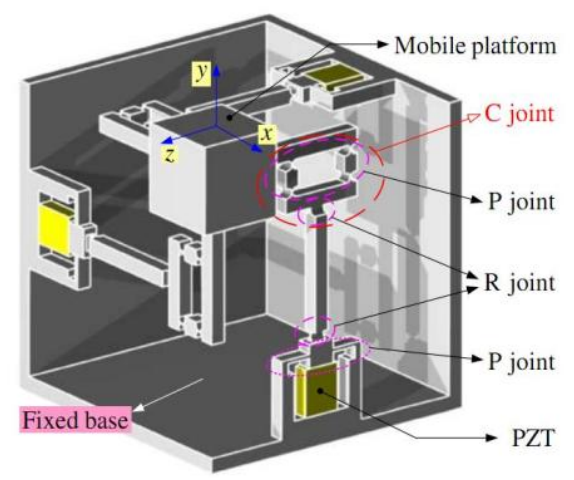

Fig. 5. Micropositioning device based on 3-PRC CPM with flexure hinges $(\mathrm{Li}, 2004)$

\subsection{The Concept of HSC Milling Machine with Hybrid Kinematic Structure Application}

At the authors workplace was designed a small-scale prototype of trivariant - which can work as a machine tool with 5 DOF as well as a robot with 6 DOF. Parallel machine is based on hybrid kinematic structure, which is characterized by connecting advantages of parallel and serial kinematic structure together - high dynamics of parallel mechanisms for positioning and high flexibility and high mobility range of serial mechanisms for orientation.

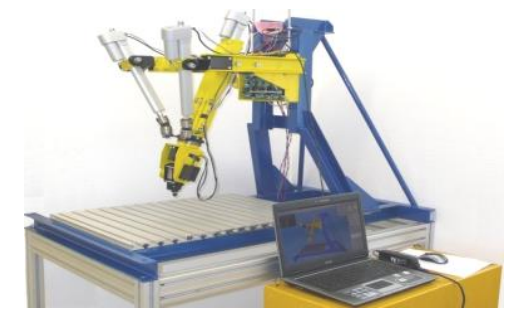

Fig. 6. Small-scale CNC machine tool builds on trivariant hybrid kinematic structure (Poppeova, 2009)

\section{CONCLUSIONS}

The main purpose of this article is to do the short summary and introduction of innovative and nonstandard applications of mechanisms based on parallel kinematic structure.

As we can see also in this short overview, the potential of the mechanisms based on parallel kinematic structure are still larger and it is not limited only for machining and manipulation. The new concepts with upgraded structures and improved parameters were developed directly for specific applications within last few years. It means that the previously used wrong way -"developed mechanism $\rightarrow$ appropriate application" was changed to more suitable one - "application required from industry $\rightarrow$ new mechanism".

\section{ACKNOWLEDGEMENTS}

This article was created by the solution of project - code ITMS 26220220046: "The Development of Parallel Kinematic Structure Prototypes for Application in the Area of Machine Tools and Robots" supported by operational program Development and research, financed from European foundation for regional progress.

\section{REFERENCES}

Li, Ch., Zhang, Y., Zhang, Y, Dai, X.: 2010, Workspace analysis of a 6-DOF Cable-driven parallel robot. Machine Design \& Research Vol. 26, 2010, ISSN 1006-2343, p. 157159 , pp. 318

Li, Y., Xu, Q.: 2009, Design and Optimization of an XYZ Parallel Micromanipulator with Flexure Hinges. Journal of Intelligent \& Robotic Systems Vol. 55, Issue 4, 2004, Springer Netherlands ISSN 0921-0296, p. 377-402,

Merlet, J.-P.: 2000, Parallel robots. Dordrecht: Kluwer Academic Publisher, 2000, pp. 327, ISBN 0-7923-6308-6.

Neugebauer, R., Putz, M., Drossel, W.-G., Lorenz, U., Blau, P.: 2002, Application of the Parallel Kinematic Machine Principle in a New Hydraulic Powered, Flexible Bending Machine for Tubes and Profiles. PKS2002 - Development Methods and Application Experiments of Parallel Kinematics; Report from the IWU Vol. 16, 2002, ISBN 3928921-76-2, p. 628-638, pp. 1042

Poppeova, V., Uricek, J., Bulej, V., Sindler, P.: 2009, The Development of Mechanism with Hybrid Kinematic Structure Prototype. In: Journal of Machine Engineering, Knowledge Based Manufacturing Machines Operation, Vol. 9, No. 3, 2009, Ed. Jerzy Jedrzejewski. Editorial Institution of Wroclaw Board of Scientific Technical Societies Federation NOT, Wroclaw 2010, Poland, p.102 - 109, ISSN 1895-7595

Pott, A., Meyer, Ch., Verl, A.: 2010, Large-scale assembly of solar power plants with parallel cable robots. International Symposium on Robotics ISR 2010: Visions are Reality, Munich, Germany, June 7 - 9, 2010, p. 999 - 1004, ISBN 978-3-8007-3273-9

Zhao, Y. Z., Zhao, T. S., Liu, L. H., Bian, H., Li, N.: 2008, Performance Analysis and Optimization of Sizable 6-Axis Force Sensor Based on Stewart Platform. Sensors: Focus on Tactile Force and Stress Sensors, ISBN: 978-953-7619-312, InTech

Zoppi, M., Li, X., Zlatanov, D., Molfino, R.: 2010, The Development of the Locomotion Subsystem of a Selfreconfigurable Mobile Fixture. Machine Design \& Research Vol. 26, 2010, ISSN 1006-2343, p. 21-28, pp. 318 